\title{
Safer toys coming, but not with Santa Claus
}

$\mathrm{P}$ roposed Canadian legislation to help stop dangerous toys from landing on store shelves, and in the hands of young children, may not be in effect before the Christmas rush.

Bill C-6, the Canada Consumer Product Safety Act, was introduced in parliament on Jan. 29, but has yet to become law. While the bill has reached the Senate, a potential fall election could delay it from receiving royal assent for many more months.

The impetus for the new act dates back to 2007 when a number of dangerous and sometimes toxic toys were pulled from stores across the country. Rick Smith, coauthor of "Slow Death by Rubber Duck" and executive director of Environmental Defence, a group that's fighting to make toys, toxin-free, says these recalls were a wake-up call for consumers and the Canadian government.

"That was a very shocking summer if you were parent and the millions and millions of toys recalled over a three-month period," says Smith. And he's not just talking about lead. "There was one brand of toy that had a significant level of a date rape drug in it; another board game had asbestos in it. It became very clear that summer, that there was a profound breakdown of consumer product protection, oversight by governments and a very severe breach of public trust by toy manufacturers."

The federal government decided it was time to change the law that ensures the safety of children's toys. The Hazardous Products Act hadn't been substantially changed to address consumer product safety since it was introduced in 1969.

Bill C-6 will give the minister of health the power to recall dangerous toys. Under the existing act, Health Canada doesn't have the authority to stop the sale of a hazardous item, it can only ask the manufacturer to voluntarily recall its toy. Smith says it's critical that the minister get these powers immediately.

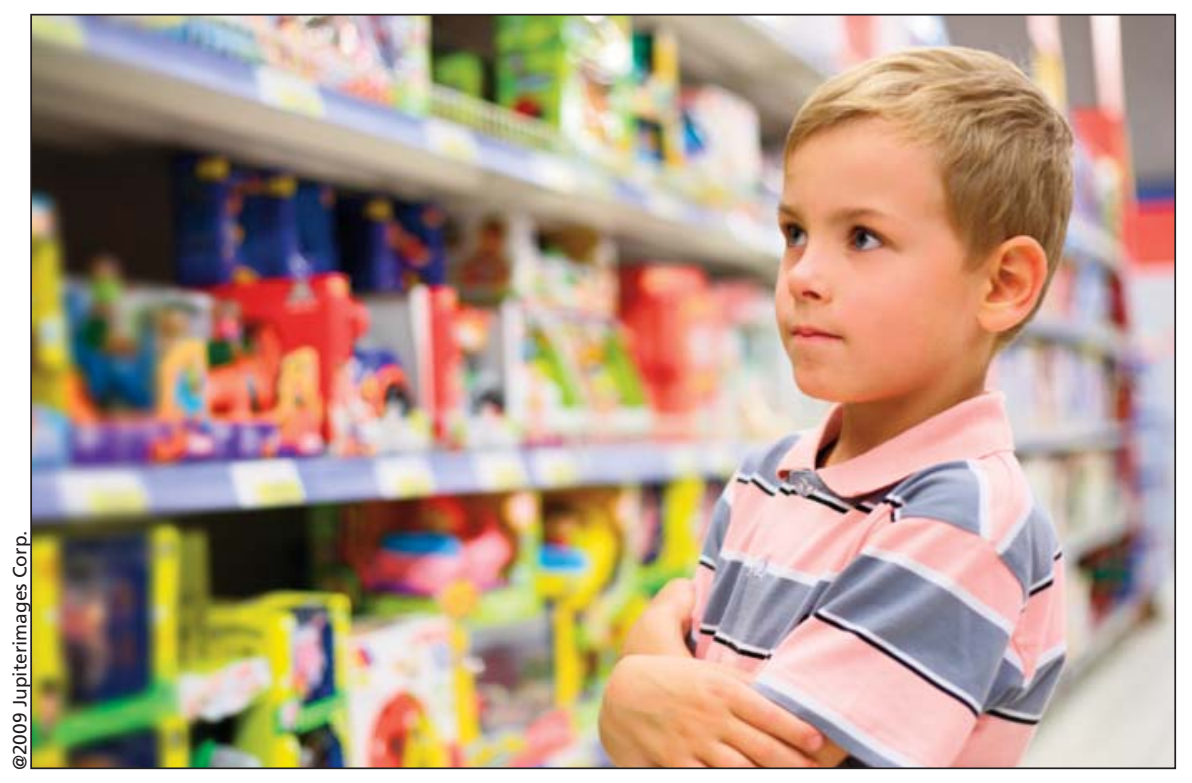

Proposed Canadian legislation to help stop dangerous toys from landing on store shelves, and in the hands of young children, may not be in effect before the Christmas rush.

"Any Canadian that I talk to, when I tell them that the government currently doesn't have the legal ability to yank products off the shelves they're incredulous. Surely it's the most basic responsibility of governments to be able to protect its citizens from poisonous toxic things. And for the government to have gone 50 years, having to rely on the good will and receptivity of the manufacturers and retailers is just insane. So that is a very important measure in the bill and the sooner that is implemented, the better."

This proposed legislation will also have a big impact on how inspectors do their work says Mark Veitch, a compliance specialist at the National Coordination Division, Consumer Product Safety Directorate of Health Canada.

"I think the new regulations are filling in holes where we've had problems in the past. A lot of it is allowing us to respond very quickly. Right now our big form of work is cooperative negotiations with the companies. It's efficient, but occasionally you run into a company where that model doesn't work well and that's what the new requirements are about."

If Bill C-6 becomes law, when a company knows it has a problem with a toy, it will be required by law to inform Health Canada. It will also force manufacturers to have documentation for their product. Under the current legislation, when a company brings a toy into the country, they are only required to meet Canadian standards; they're not required to test their product. With Bill C-6, when Health Canada requests a test report, the company must deliver it.

And companies that repeatedly violate the law with be fined any where from $\$ 250000$ to $\$ 5$ million and/or face imprisonment for six months to five years, depending on the violation. Veitch insists these fines will be used sparingly: "It's a sliding scale, they can be quite significant. I think it's not really about the dollars. It's more about that penalties are aimed at the worst players on the marketplace. Those would be the companies that have made a business choice to sell product that's dangerous because there's money to be made on that product." 
Health Canada's Inspectors will also start to collaborate with Customs officers at the border, to increase information sharing. Health Canada will also place staff at the borders to access products coming into the marketplace. That means more inspectors will need to be hired.

The 2008 federal budget allocated approximately $\$ 12$ million for product safety, including enhanced toy testing. Much of that money will be spent on doubling the number of inspectors over five years; since 2007, Health Canada has hired 21 new staff. There are now 61 inspectors Canada-wide and 19 positions still to be filled.

Those federal dollars are also being used to increase testing on toys. In the past two years, 459 toys were tested to determine if they comply with current standards. In 2006 and 2007, the year before all of the recalls, only 82 toys were tested. The 459 toy tests were both planned inspections and ad hoc. For example, 21 different magnetic toys for children under three were tested, focusing on choking hazards. So far two recalls have been posted. There were 30 tests done on plush toys, checking on the safety of small parts, like eyes and noses: 18 were found to be non-compliant. Ninety-four toys were tested for heavy metals applied in the surface coatings. Inspectors focused on prohibited metals under the existing Act, including lead, mercury, antimony, arsenic, cad, selenium and barium. Twelve toys failed that test.

The increase in testing happened for many reasons. Companies and public awareness grew, especially with hazards relating to lead in surface coatings, prompting regulators around the world and the companies themselves to test more.

Companies also took a proactive approach to avoid recalls that may cause a black mark on their reputations. In 2007, former health minister Tony Clement launched the Consumer Product Safety Recalls website. Since the site went online, Health Canada has received a greater number of complaints from the public, which has lead to an increased number of investigations, sampling, testing and enforcement.

While the executive director of Environmental Defence credits the government for making huge strides, Smith says he'd hoped the law would be stronger. "We were hoping for instance that there would be better mandatory labeling provisions. We think that consumers are smart and engaged and want to know exactly what's in the products that they're buying. So, we're disappointed that the labeling provisions in the new consumer protection act are not stronger." But Smith adds, "You shouldn't have to be a chemical engineer to shop for toys for your children. Ultimately the only answer is for government to better regulate." - Hannah Thibedeau, Ottawa, Ont.

DOI:10.1503/cmaj.109-3003 